\title{
'N FUNKSIONELE DENKBENADERING IN DIE VERPLEEGKUNDE
}

Annatjie Botes

\section{INLEIDING}

Met die funksionele denkbenadering word die dienskarakter en praktykgerigtheid van wetenskapsbeoefening bekJemtoon. Die bruikbaarheid en toepassing van die kennis vir die verbetering van die praktyk is die oogmerk. Die wetenskaplike wil binne bepaalde konteks voorskrifte gee oor hoe daar in die praktyk gehandel behoort te word. Die sogenaamde skeiding tussen die teorie en praktyk het vervaag.

Die vraag met betrekking tot die haalbaarheid van die funksionele denkbenadering in die verpleegkunde handel oor wat die doelstellings van wetenskapsbeoefening behoort te wees. Stoker (1969:142) onderskei tussen die besondere en algemene doelstellings van die wetenskap. Die besondere doelstellings kan getipeer word as verken, beskryf en verklaar. Die wetenskaplike in die verpleegkunde verken, beskryf en verklaar die verplegingspraktyk ten einde 'n geldige begrip van die praktyk daar te stel. Dit wil voorkom of daar 'n groot mate van ooreenkoms tussen wetenskaplikes is wat die besondere doelstellings van die wetenskap betref. Daar bestaan egter meningsverskille oor die algemene doelstellings van die wetenskap. Die debatering sentreer veral rondom die scientistiese (suiwer navorsing) en pragmatiese (toegepaste navorsing) doelstellings van die wetenskap. Die voorstanders van 'n scientistiese doelstelling vir die wetenskap huldig die mening dat wetenskapsbeoefening gaan oor kennis ter wille van die kennis. Die taak van die wetenskap is die versameling van sistematiese kennis. Die groep huldig die mening dat die wetenskaplike geen betrokkenheid en verantwoordelikheid ten opsigte van die toepassing van die kennis in die praktyk het nie. Hulle verantwoordelikheid eindig by die akkumulasie van geldige kennis. Daarenteen is die wetenskaplikes wat die pragmatiese doelstelling van die wetenskap voorstaan van mening dat die geldige kennis bruikbaar gemaak moet word deurdat dit onder andere in die praktyk toegepas word met die oog daarop om die spesifieke praktyk te verbeter. Volgens die sogenaamde pragmatiese benadering is die wetenskapsbeoefenaar mede-verantwoordelik en betrokke by die praktyk. Die funksionele denkbenadering sou kon aansluiting vind by die pragmatiese doelstelling van wetenskapsbeoefening.

\section{OPSOMMING}

Die funksionele denkbenadering her die toepassing van kennis vir die oplossing van probleme in die praktyk ten doel. Ten einde oor die haalbaarheid van die funksionele denkbenadering in verpleegkunde te besluit is dit nodig dat daar besin word oor die verhouding tussen die verplegingspraktyk, die verpleegkunde en die filosofie van verpleeg. kunde. Indien dit sou blyk dar die denkbenadering aangewese is moet daar oor die metodologiese implikasies vir verpleegkundige navorsing besin word.

\section{ABSTRACT}

The aim of the functional approach is the application of knowledge to the solution of problems in nursing practice. In order to decide whether the functional approach is appropriate in nursing science it is necessary to study the relationship between nursing practice, nursing science and the philosophy of nursing science. If the functional approach seems appropriate, thought should be given to methodological implications for nursing research.

Ten einde die haalbaarheid van die funksionele denkbenadering in die verpleegkunde te bepaal is dit nodig dat daar oor die volgende aspekte besin word, naamlik:

- die verhouding tussen die verplegingspraktyk, die verpleegkunde en die filosofie van verpleegkunde:

- die wetenskapsfilosofiese uitsprake met betrekking tot die sogenaamde funksionele denkbenadering; en

- die ontwikkeling van verpleegkunde as wetenskap.

Indien dit sou voorkom dat verpleegkunde as wetenskap 'n funksionele denkbenadering behoort te volg sal daar oor die metodologiese implikasies van die funksionele denkbenadering in die verpleegkunde besin moet word.

\section{DIE VERHOUDING TUSSEN DIE VERPLEGINGSPRAKTYK - DIE VERPLEEGKUNDE EN DIE FILOSOFIE VAN VERPLEEGKUNDE}

Indien verpleging bedink word as aktiwiteite wat op drie vlakke of ordes plaasvind kan die verhouding tussen die drie ordes deur figuur 1 voorgestel word.

\section{Die Verplegingspraktyk}

Die eerste orde verteenwoordig die empiriese werklikheid. Binne verpleegkundige konteks is dit die verplegingspraktyk. Dit is die vlak of orde waar die verplegingshandelinge plaasvind en is die studie-objek vir wetenskapsbecefening in die verpleegkunde. Die wetenskapsbeoefenaar ondersoek probleme in die verplegingsprakıyk om tot 'n geldige begrip van die aspek van die verplegingspraktyk te kom en probeer sodoende oplossings vir die probleem vind. Om die navorsingsonderwerp binne verpleegkundige verband te stel is dit nodig dat die wetenskaplike in die verpleegkunde uitklaring kry oor die presiese doel van verpleging, die tyd-ruimtelike konteks waar die verplegingshandelinge plaasvind asook die aard van die handelinge. Sodoende kan konsepte wat aanverwand aan ander dissiplines is binne verpleegkundige konteks beskryf en ondersoek word.

Verpleging is ' $n$ professie. Wanneer daar oor die kriterium van 'n professie besin word is daar sekere aspekte wat voorop staan. 'n Professie het sy ontstaan uit die behoefte van die gemeenskap aan daardie spesifieke diens. Die lede van die beroep verbind hulle tot diens aan die mensdom asook aan die bereiking van 'n vlak van kundigheid om daardie diens te voorsien. Die daarstelling van 'n kennisinhoud om die diens te lewer word juis deur navorsing bereik. Die lede van die beroep verbind hulle dus by implikasie tot voortgesette navorsing om aan die veranderende behoeftes van die gemeenskap te voorsien. Die verbintenis tot navorsing behels die uitvoer van die navorsingsproses self asook die toepassing van die navorsing of nuwe kennis in die praktyk. Dit beteken dat die wetenskapsbeoefenaar of navorser in die verpleegkunde nie onverskillig en onbetrokke tot die verplegingspraktyk kan staan nie. Net so het die verpleegpraktisyn 'n professionele 
verantwoordelikheid om die navorsing in die praktyk toe te pas.

Die verplegingshandelinge is gegrond op die kennisinhoud van verpleegkunde, maar in die praktyk vind verplegingshandelinge plaas wat op sogenaamde voor-wetenskaplike interpretasies van die verpleegkundige en die verpleegassistente berus. Die verplegingshandelinge wat op die voor-wetenskaplike interpretasies berus konstitueer in 'n groot mate die verplegingspraktyk soos wat dit in realiteit beoefen word. Dit is dus noodsaaklik dat die wetenskapsbeoefenaar van die voor-wetenskaplike interpretasies in die verplegingspraktyk kennis neem en die interpretasies sal verken, beskryf en analiseer vir 'n beter verstaan van die verplegingspraktyk soos wat dit in die werklikheid beoefen word.

Die verplegingspraktyk beskik oor sekere kenmerke wat metodologiese eise aan die wetenskapsbeofening in die verpleegkunde stel. Botes (1989:109 ev) beskryf die volgende eienskappe wat metodologiese implikasies vir wetenskapsbeoefening in die verpleegkunde het:

- die verplegingsinteraksie is interpersoonlikverhoudingsgebonde. Dit beteken dat wat ook al in die verplegingspraktyk ondersoek word handel oor die mens in 'n bepaalde soort interaksie met mekaar. Die ontledingseenheid van verpleegkundige navorsing is dus die mens betrokke by een of ander verplegingshandeling:

- menslike handelinge is intensioneel en be tekenisbelaaid. Dit bring mee dat wat waargeneem word nie altyd die volle verhaal vertel nie en dat dat sekere eise aan die metodes van data-insameling in die verpleegkunde gestel word;

- aangesien die verplegingsinteraksie doelgerig is en doeistellings verband hou met dit waaraan waarde geheg word is die verplegingsinteraksies waardegebonde. Waardes geld dus as handelingsriglyne en vorm ' $n$ intergrale deel van wetenskapsbeoefening;

- die verplegingsinteraksie is konteksgebonde (tyd-ruimtelik en kultuur-histories) en die verplegingsinteraksie kan nie buite die konteks en vanuit die verwysingsraamwerk van diegene betrokke by die handeling verstaan word nie; en

- die verplegingsinteraksie is dinamies en veeldimensioneel Dit blyk ' $n$ saak van onmoontlikheid te wees om al die samehangende faktore saam te trek en te orden. Die gevaar is 'n te enge interpretasie van die verplegingspraktyk en die voorlopigheid van die uitsprake in verpleegkunde moet in die opsig erken word.

\section{Die Verpleegkunde}

Die tweede orde verteenwoordig die aktiwiteite van wetenskapsbeoefening om sodoende die teorie van die wetenskap daar te stel. Die aktiwiteite van wetenskapsbeoefening behels navorsing en teorievorming. Wetenskapsbeoefening in die verpleegkunde is ' $n$ metapraktiese aktiwiteit. Dit beteken dat die wetenskapsbeoefenaar probleme soos wat dit in die verplegingspraktyk voorkom verken, beskryf en verklaar en oplossings vir die probleme te vind. Wetenskapsbeoefening vind nie in isolasie plaas nie, maar fokus op 'n bepaalde aspek in die werklikheid en spesifieke aannames vorm ' $n$ integrale deel van wetenskapsbeoefening. Die wetenskapsbeoefenaar is ook nie onbetrokke by die verplegingspraktyk nie, maar is mede-verantwoordelik vir die praktyk.

Wetenskapsbeoefening fokus enersyds op die werklikheid en staan bekend as navorsing oor eeste orde verskynsels. Andersyds fokus wetenskapsbeoefening op die konstrukte van navorsing en staan bekend as navorsing oor tweede orde verskynsels. Voorbeelde van navorsing oor tweede orde verskynsels is modelbou en teorievorming.

Mouton \& Marais (1988:7) beskryf die volgende dimensies van wetenskapsbeoefening, naamiik:

- die sosiologiese dimensie wat op wetenskapsbecefening as 'n gemeenskaplike handeling dui;

- die ontologiese dimensie wat die gerigtheid van wetenskapsbeoefening op 'n bepaalde aspek van die werklikheid dui;

- die teleologiese dimensie wat op die doelgerigte aard en intensionaliteit van wetenskapsbecefening dui;

- die epistomologiese dimensie wat op die doel van wetenskapsbeoefening as die gee van geldige en werklikheidsgetroue uitsprake dui; en

- die metodologiese dimensie wat op die kritiese, gebalanseerde, nie-sydige en sistematiese werkswyse van die wetenskap dui.

Die terrein van metodologiese besinning as 'n tweede orde aktiwiteit word deur Smith (1988:6) in figuur 2 voorgestel. Die beginpunt en eindpunt word die determinante van navorsing genoem. Die determinante is bepalend vir die navorsingsbesluite. Die eise en kenmerke van die studieterrein, die navorsingsdoelstelling en -strategie asook die aannames van die navorser verteenwoordig die sogenaamde determinante van navorsing. Die navorsingsbesluite word met inagneming van die determinante geneem. Die besluite van navorsing word gemaak in terme van die navorsingsonderwerp, probleemstelling, konseptualisering, operasionalisering, data-insameling, -analise en -interpretasie.

\section{Die filosofie van verpleegkunde}

Die filosofie van verpleegkunde is 'n metatoeretiese aktiwiteit en behels die analise, ordening en evaluering van konsepte, aannames, beskouings en metodes wat op die eerste en tweede ordes aangetref word. So kan daar wetenskapsfilosofies besin word or die doel met, metodes van en kriterium vir waarheid van wetenskapsbeoefening in die verpleegkunde.

\section{WETENSKAPFILOSOFIESE UITSPRAKE MET BETREKKING TOT DIE FUNKSIONELE DENKBENADERING}

Wetenskapsfilosofie stel vrae oor die epistomologiese, die metodologiese, die logiese en die etiese aard van die wetenskap en stel raam werke waarbinne genoemde vrae beantwoord kan word. Binne die wetenskapsfilosofie van die geesteswetenskappe het daar in die afgelope twee dekades dramatiese veranderinge plaasgevind. Samevattend word eietydse wetenskapfilosofiese modelle deur twee tradisies oorheers, naamlik die die naturalistiese en die anti-naturalistiese of humanistiese benaderings. Die humanistiese benadering beweer dat die mens nie op dieselfde wyse as natuurverskynsels verstaan, verklaar en voorspel kan word nie. Die intensionele en willekeurige aard van menslike gedrag word as rede aangevoer. Teenoor die humanistiese benadering staan die naturalistiese benadering wat glo dat menslike verskynsels nie essensieel van natuurverskynsels verskil nie en da menslike gedrag net soos natuurverskynsels verklaarbaar, voorspelbaar en veraigemeenbaar is.

Vervolgens word ' $n$ interpretasie van uitsprake oor die vernaamste wetenskapfilosofiese modelle met betrekking tot die funksionele denkbenadering weergegee.

\section{Die Positivisme}

Die positivistiese model neem sy vertrekpunt in dit wat empiries toetsbaar is (Comte, 1974:27) en skep sodoende 'n bepaalde dissipline in die konstrukte van die wetenskap. Sodanige dissipline bring 'n materialistiese bekouing van die wetenskap mee wat geen ruimte laat vir waarde-vraagstukke nie. Dit laat die wetenskapsbecefenaar neutraal staan met geen sosiale verantwoondelikheid of aan voeling vir die vervlegtheid van sosiale verskynsels nie. So word 'n leemte gelaat in die etiese verantwoordelikheid van die wetenskap en die wetenskapsbeoefenaar. In bree trekke huldig die positivistiese model scientistiese doelstellings vir die wetenskap, al hoewel latere positiviste soos Emst Nagel en Richard Ruder, annvaar het dat bepaalde waardes en aannames 'n integraie deel van wetenskapsbeoefening vorm (Mouton, 1989:129). Volgens die model stop die wetenskaplike se verantwoordelikheid by die akkumulasie van wetenskaplike kennis. Die navorser het dus geen verantwoordelikheid ten opsigte van die toepassing van die kennis in die praktyk nie.

Dit beteken egter nie dat wetenskapsbeoefening vanuit 'n funksionele denkbenadering nie van die metodes van die positivistiese model 
kan gebruik nie. Inteendeel vereis die verbetering van die praktyk tog beheer oor die bepaalde praktyk wat veral deur sekere kwantitatiewe metodes wat verband hou met die positivistiese model bewerkstellig kan word.

\section{Kritiese rasionalisme van Karl Popper}

Popper glo dat die sosiaal-wetenskaplike nie onbetrokke kan wees by dit wat hy waarneem nie en dat waarde-oordele, partydigheid en subjektiwiteit nie van die ondersoeker weggeneem kan word nie (Popper, 1965:27).

\section{Kuhn se wetenskapsfilosofie}

Die vernaamste bydrae van Kuhn is gelee in sy paradigma-begrip wat impliseer dat die wetenskaplike hom nie kan losmaak van sekere waardes en aannames nie. Daar is dus nie sprake van onbevange en onbetrokke waarneming nie (Kuhn, 1970).

\section{Die fenomenologiese benadering}

Die fenomenologie verteenwoordig die denktradisie wat besonder sterk die verskil tussen wetenskapsbeoefening van die natuur- en sosiale wetenskappe beklemtoon. In die geesteswetenskappe word daar na kontekstuele of partikulier geldende bewerings gesoek in teenstelling met die natuurwetenskappe wat na universele of veralgemeende begrippe of kennis soek. Die ondersoeker is op soek na nuwe betekenis en samehang (Smith, 1988).

\section{Die kritiese hermeneutiek}

Die interpretasie van menslike handeling is een van die aspekte wat sentraal staan in die kritiese hermeneutiek. Menslike handelinge vind in 'n bepaalde konteks plaas en die interpretasie van sodanige handelinge kan nie buite daardie konteks gedoen word nie. Volgens Taylor (1985:93) het die lede van 'n samelewing 'n pre-teoretiese interpretasie van hul samelewing en die menslike handelinge word juis deur hierdie pre-teoretiese interpretasies gerig. Die stelling het vereikende gevolge vir die teorie en praktyk. Dit impliseer dat die praktyk teorie voor-wetenskaplike interpretasie het waarmee die teorie rekening moet hou aangesien die werklikheid deur hierdie interpretasies gekonstitueer 'vord. Die doel van die teorie behoort te wees om die voor-wetenskaplike interpretasies aan te vul, te wysig en te kritiseer. Die praktyk word hiermee medebepalend vir die geldigheid van 'n teorie.

\section{Die kritiese teorie}

Die kritiese teorie stel hom onder andere as praktykgerig en stel dit dat waardes nie onafhanklik van menslike besl uitneming staan nie. Teoretiese stelling is nie waardevrye beskrywings nie, maar eerder waardegelaaide voorskrifte van wat behoort gedoen te word (Romm.1987).

\section{Stelselteorie}

Die stelselteorie vertrek vanuit die standpunt dat die verskillende komponente van die samelewing in verhouding tot mekaar bestudeer word, aangesien die verskillende komponente mekaar beinvloed (Kriek, 1987)

\section{DIE ONWIKKELING VAN' $\mathbf{N}$ WETENSKAP}

Wanneer daar besin word oor die doelstelling van wetenskapsbeoefening in die verpleegkunde behoort die werk van Van Peursen (1976:9) ook in berekening gebring te word. In die ontwikkeling van die Westerse kultuurgeskiedenis (onder andere wetenskap) onderskei Van Peursen tussen die mitiese-, ontologiese -en funksionele denkfase.

\section{Mitiese fase}

In die mitiese fase is slegs bevestiging gesoek dat iets wel bestaan. Die bestaanswyse is in tradisie geanker. Die tradisie het as onbevraagde gesagsbron gegeld. Verskynsels is verklaar aan die hand van bonatuurlike magte. Kritiese en rasionele verantwoording het die sekuriteit versteur en tradisies verbreek. Hier is dus duidelik sprake van ervaring-en geloofskennis. In die geskiedenis van die verpleegkunde en geneeskunde as wetenskappe vind ons duidelik die denkfase waar siekte en menslike gedrag toegeskryf was aan bonatuurlike kragte.

\section{Ontologiese fase}

As verset teen die mitiese kragte wat die mens beheer het het die ontologiese denkhouding ontstaan. Die mens wou selfstandig die saak gaan ondersoek. Die wat-vraag is probeer verklaar aan die hand van wat waarneembaar is. Die teoretiese bespiegeling van die sigbare en die onsigbare kom na vore. Die wat-vraag is aanvanklik in isolasie gevra en die algemene en universele aard van die denke is 'n kenmerk van die fase. In die verpleegkunde as wetenskap is daar nog baie wat-vrae wat gevra moet word. Alhoewel die vrae prakties gesproke onvrugbaar is, dien dit juis as vertrekpunt vir die funksionele denkfase.

\section{Funksionele denkfase}

In die derde fase is die mens nie meer vasgevang in die mitiese houding nie, bestudeer die werklikheid nie meer onbetrokke nie, maar wil nuwe verhoudings en betrokkenheid vind tot alles wat hom omring. Die term funksioneel kan as middel dien om 'n groot hoeveelheid verskynsels saam te vat en te begryp. Die funksionele denkbenadering soek betekenis in samehang en funksie. Persoonlike betrokkenheid word die kriterium en daar word in plaas van op die algemene op die spesifieke gefokus. Waar dit by die ontologiese oor die synvraag gehandel het kan die sin-vraag van die funksionele slegs in betrokkenheid gevra word. Die sin lê in nuttigheid, bruikbaarheid en doeltreffenheid. Die funksionele staan nie passief tot die wereld nie maar is aktief be- trokke en mede-verantwoordelik. In die funksionele gaan dit ook oor kennis wat verower word maar daar het egter 'n verskuiwing vanaf die teorie na die praktyk plaasgevind. Die kennis gaan dus om insig, begrip en beheer van die praktyk. Die hoe-vraag ontstaan in die verband. Die wetenskap binne die funksionele denkhouding word praktykgerig. Die doel word orn handelingsgerigte voorskrifte te gee oor hoe daar in die praktyk gehandel moet word ten einde die praktyk meer effektief te mak. Die voorskrifte is egter waardebelaaide voorskrifte en die waardes van diegene betrokke by die handelinge moet in aanmerking geneem word by die gee van sodanige voorskrifte. Dit bring mee dat die voorskrifte slegs binne ' $n$ bepaalde konteks gegee kan word waar die waardes van diegene betrokke by die handelinge in berekening gebring word.

\section{DIE IIAALBAARHEID VAN DIE FUNKSIONELE DENKBENADERING IN DIE VERPLEEGKUNDE}

Na aanleiding van die voorafgaande kan daar vervolgens besin word oor die haalbaarheid van die funksionele denkbenadering in die verpleegkunde. Vanuit die perspektief van verpleging as professie is dit wenslik sowel as 'n vereiste dat die beroep hulle verbind tot die daarstelling van 'n teoretiese kennisinhoud vir die verpleegkunde. Sodanige kennisinhoud behoort dan as riglyn vir die verplegingshandelinge in die praktyk te dien. Die kennisinhoud en by implikasie die verplegingshandelinge behoort aan die behoeftes van die mens te voorsien om 'n gehalte diens aan die mensdom te lewer. Die wetenskapsbeoefenaar in die verpleegkunde moet haarself tot die uitvoer van navorsing verbind om 'n kennisinhoud vir verpleegkunde te verseker en die verpleegkundige praktisyn is weer verbind tot die toepassing van hierdie kennis in die praktyk. Ten einde 'n geldige kennisinhoud vir verpleegkunde daar te stel moet die navorser tred hou en betrokke wees by die behoeftes van die mens wat verpleging benodig. Vanuit uit 'n professionele perspektief van verpleging wil dit voorkom of die funksionele denkbenadering aangewese is aangesien die diensmotief sentraal staan by die kriteria van 'n professie en die funksionele denkbenadering.

Wanneer die verhouding van die teorie en praktyk in perspektief geneem word daar gevind dat wetenskapsbeoefening ' $n$ meta-praktiese aktiwiteit is. Wetenskapsbeofening is dus praktykgerig en handel oor die praktyk. Dit probeer oplossings vir die probleme in die praktyk vind deur die probleme te verken, beskryf en verklaar en wil voorskrywend wees oor hoe daar in die praktyk gehandel behoort te word om die probleme die hoof te bied. Die ontologiese dimensie van wetenskapsbeoefening dui op die wetenskap se gerigtheid op 'n bepaalde aspek van die werklikheid, naamlik die verplegingspraktyk. 
Dit maak die wetenskapsbeoefenaar betrokke en mede-verantwoordelik in die praktyk.

Die verpleginspraktyk is die studie-objek van wetenskapsbeoefening in die verpleegkunde. Die verplegingspraktyk word onder meer gekonstitueer deur die sogenaamde voor-wetenskaplike interpretasies van die verpleegpraktisyn. Die wetenskapsbeofenaar moet haar ten opsigte van hierdie voor-wetenskaplike interpretasies vergewis ten einde instaat te wees om tot 'n beter gegrip van die verplegingspraktyk te kom. Dit vereis betrokkenheid van die wetenskapsbeoefenaar by die verplegingspraktyk sodat sy na haar navorsing handelingskrigte voorskrifte kan gee oor hoe daar verpleeg behoort te word. Dit mak die wetenskapsbeoefenaar mede-verantwoordelik vir die verplegingspraktyk. Die wetenskaplike in die verplegkunde behoort die sogenaamde voor-wetenskaplike interpretasies te verken en beskryf ten einde in staat te wees om om die interpretasies te bevestig, te kritiseer en te wysig.

Vanuit die verhouding tussen die verplegingspraktyk en die verpleegkunde lyk die funksionele denkbenadering aangewese omdat dit juis wetenskapbeoefening praktykgerig maak en betrokkenheid voorstaan. Verder akkomodeer die funksionele denkbenadering ook die basiese kenmerke van die verplegingspraktyk, naamlik die interpersoonlik-verhoudingsgebondenheid, waarde- en konteksgebondenheid asook die veeldimensionele en dinamiese aard van verpleging.

Wanneer dit by uitsprake van die wetenskapsfilosofie kom vind ons dat dit veral die meer resente modelle van geesteswetenskaplike oorsprong is wat wegbreek van die suiwer scientistiese doelstelling van die wetenskap en sy daarmee gepaardgaande skeiding en onbetrokkenheid tussen die teorie en praktyk. Sodanige modelle oorbrug die skeiding tussen die teorie en die praktyk en akkomodeer die kenmerke en eise van sosiale verskynsels. Teoretiese stellings is konteksgebonde en waardebelaaide voorskrifte vir handelinge in die praktyk. Die doelstellings is pragmaties met nuttigheid, bruikbaarheid en die verbetering van die praktyk as kriteria vir geldigheid. ' $n$ Moderne benadering in die wetenskapsfilosofie is ' $n$ ja vir die metodes van die natuurwetenskappe indien dit die ken. merke en eise van die sosiale verskynsel akkomodeer.

Wanneer daar vanuit die perpektief van die ontwikkeling van 'n wetenskap gekyk word, kom 'n mens tot die besef dat daar nog heelwat wat-vrae in die verpleegkunde beantwoord moet word. Die verskynsel verpleging sal keer op keer weer opnuut in nuwe verhouding en funksie bekyk moet word ten einde 'n geldige begrip van verpleging daar te stel. Verpleegkunde as wetenskap kan dit egter nie bekostig om by die wat-vrae stil te staan nie, aangesien dit prakties gesproke onvrugbaar is Dit is dan juis die kennis van die ontologiese denkhouding wat as vertrekpunt dien vir die funksionele denkbenadering. Die wat-vrae behoort dus in verhouding en met pragmatiese doelstellings gevra te word.

Na die voorafgaande besinning oor die haalbaarheid van die funksionele denkbenadering wil dit voorkom dat verpleegkunde nie anders kan as om 'n funksionele denkbenadering in sy wetenskapsbeoefening te volg nie.

\section{DIE METODOLOGIESE IMPLIKASIES VAN DIE FUNKSIONELE DENKBENADERING}

Die metodologiese implikasies van die funksionele denkbenadering in die verpleegkunde sal na aanleiding van 'n model vir wetenskapsbeoefening in die verpleegkunde (figuur 3 ) beskryf word.

Die navorser in die verpleegkunde is in dialektiese interaksie met die verplegingspraktyk en neem in die verband kennis van die voorwetenskaplike interpretasies van die verpleegpraktisyn en die kenmerke van die praktyk wat eise aan die aard van wetenskapsbeoefening stel. Aangesien waardes ' $n$ integrale deel van wetenskapsbeoefening is word daar deur selektiewe internalisering waardes vanuit die derde orde gekies as determinant vir die aard van navorsingsbesluite wat geneem moet word. Hierdie waardes wat as aannames gestel word moet die basiese kenmerke van die verplegingspraktyk akkomodeer.

Binne 'n funksionele denkbenadering verskuif die navorsingstrategie vanaf die universele na die kontekstuele aangesien teoretiese stellings waardegelaaide handelingsvoorskrifte is wat voorsiening moet maak vir die waardes van diegene wat by die handelinge betrokke gaan wees. Die navorsingsdoelstelling word behalwe vir verken, beskryf en verklaar spesifiek voorskrywend.

Die navorsingsonderwerp, probleemstelling asook konseptualisering en operasionalisering moet binne die aard, konteks en doel van verpleging gestel en gekies word. Die betrokkenheid van die wetenskaplike by die praktyk is essensieel en die verpleegpraktisyn kan nie buite rekening gelaat word nie.

Die metodes van data-insameling moet aansluit by die navorsingsstrategie en -doelstelling. Konsensus moet met die praktisyn bereik word oor die bruikbaarheid van die kennis vir die verbetering van die verplegingspraktyk. Al die losstaande stellings in verpleegkunde moet georden en saamgevoeg word in konseptuele raamwerke om 'n bruikbare kennisinhoud vir die verpleegkunde daar te stel. Die teoriee wat so verkry word moet praktykrigtende teoriee wees. Dit impliseer dus dat alle navorsingsuitsprake nie sommermeer in die praklyk toegepas word nie, maar dat al die verbandhoudende uitsprake sistematies georden en saamgevoeg word tot 'n model en teorie or daardie onderwerp. Sodanige teoriee wat dan die betrokke verskynsel verklaar kan dan in die verplegingspraktyk toegepas word.

Die verpleegkundige navorser behoort die resultaat van haar navorser aan die verpleegkundige praktisyn bekend te stel. Dit sal voorkom dat verpleegkundige navorsing bloot vir die verkryging van kennis gedoen word en waarskynlik op die boekrak bly staan. Die taak van die wetenskapsbeoefenaar en die praktisyn in verpleging is wedersydse betrokkenheid en verantwoordelikheid vir die versameling van 'n geldige kennisinhoud vir verpleegkunde waarmee die verplegingspraktyk verbeter kan word. Die verpleegkundige is vakkundig, eties en professioneel daartoe verbind.

\section{BIBLIOGRAFIE}

BOTES, A C 1989: 'n Model vir wetenskapsbeoefening in die verpleegkunde. Johannesburg: Randse Afrikaanse Universiteit. (D.Cur-proefskrif)

COMTE, A 1974 (1830-1846): The positive philosophy. Translated by H Martineau 1974 New York: AMS Press.

KRIEK, D J 1987: Die stelselteorie (In: Snyman, JJ \& Du Plessis, PGW red. 1987: Wetenskapsbeelde in die geesteswetenskappe. Pretoria: Raad op Geesteswetenskaplike Naworsing, 221-236)

KUHN, TS 1970: The structure of scientific revolutions. London: University of Chicago Press.

MOUTON, J 1989: Resensie artikel: Paradigmas in die wetenskappe. Koers.

Potchefstroom: Potchefstroomse Universiteit vir Christelike Hoer Onderwys

MOUTON, J \& MARAIS, H C 1988: Metodologie van die geesteswetenskappe: Basiese begrippe. Pretoria: Raad op Geestesweten skaplike Naworsing.

POPPER, KR 1965: Conjections and reflutations. London: Routlegde \& Kegan Paul.

ROMM, N 1987: Habermas se wetenskapsteorie (In: Snyman, JJ \& Du Plessis, PGW red 1987: Wetenskapsbeelde in die geestes wetenskappe. Pretoria: Raad op Geestes wetenskaplike Naworsing 179-190).

SMITH, DPJ 1988: Teorie en praktyk van die opvoedkunde. Johannesburg: Randse Afrikaanse Universiteit. (Monografie).

STOKER, HG 1969: Beginsels en metodes in die wetenskap. Johannesburg: Boekhandel De Jong.

TAYLOR, C 1985: Social theory as practice (In: Taylor, C 1985: Philosophy and social science. Philosophical Papers, volume 2. Cambridge: CUP 91-115).

VAN PEURSEN, CA 1976: Cultuur in stroomversnelling. Strategie van de cultuur. Amsterdam: Elsevier. 


\section{FIGUUR 1}

Die verhouding tussen die verplegingspraktyk.

Die verpleegkunde en die filosofie van verpleegkunde.

\begin{tabular}{|c|l|}
\hline Derde Orde & $\begin{array}{l}\text { Die Filosofie van verpleegkunde } \\
\text { (Meta-metodologiese/Meta-teoretieseaktiwiteit) }\end{array}$ \\
\hline Tweede Orde & $\begin{array}{l}\text { Die Verpleegkunde } \\
\text { (Meta-praktiese/Metodologiese aktiwiteit) } \\
\text { (Wetenskapsbeoefening) }\end{array}$ \\
\hline Eerste Orde & $\begin{array}{l}\text { Werklikheid } \\
\text { Die Verplegingspraktyk(Interaksie) } \\
\text { (Voor-wetenskaplike Interpretasies) }\end{array}$ \\
\hline
\end{tabular}

FIGUUR 2.

Die terrein van metodologiese besinning.

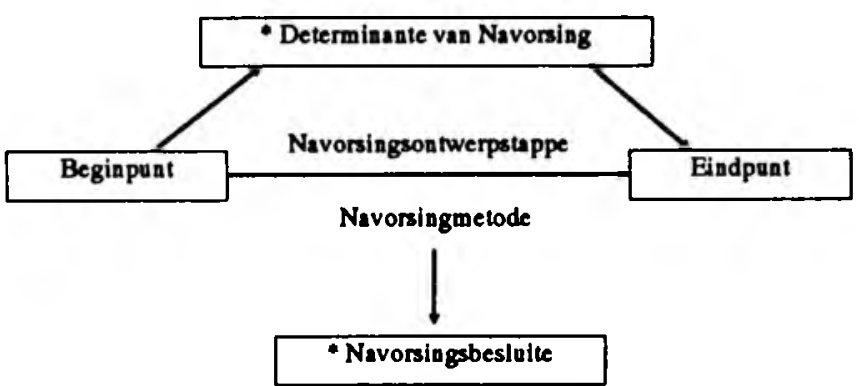

\section{FIGUUR 3.}

'n Model vir Wetenskapsbeoefening In die Verpleegkunde. 